\title{
Topical nasal decongestant oxymetazoline (0.05\%) provides relief of nasal symptoms for 12 hours*
}

\author{
Howard M. Druce', David L. Ramsey², Sanjay Karnati², Andrew N. Carr ${ }^{3}$ \\ 'Ear Nose and Throat Care P.C., Somerville NJ 08876, USA \\ 2 Procter \& Gamble, Personal Health Care Division, Mason, OH 45040, USA \\ ${ }^{3}$ Procter \& Gamble, Cincinnati, OH 45221, USA
}

Rhinology 56: 4, 343-350, 2018

https://doi.org/10.4193/Rhin17.150

*Received for publication:

July 12, 2017

Accepted: March 9, 2018

Background: Nasal congestion, often referred to as "stuffy nose" or "blocked nose" is one of the most prevalent and bothersome symptoms of an upper respiratory tract infection. Oxymetazoline, a widely used intranasal decongestant, offers fast symptom relief, but little is known about the duration of effect.

Methodology: The results of 2 randomized, double-blind, vehicle-controlled, single-dose, parallel, clinical studies (Study 1, $\mathrm{n}=67$; Study $2, n=61)$ in which the efficacy of an oxymetazoline $(0.05 \%$ Oxy) nasal spray in patients with acute coryzal rhinitis was assessed over a 12-hour time-period. Data were collected on both subjective relief of nasal congestion (6-point nasal congestion scale) and objective measures of nasal patency (anterior rhinomanometry) in both studies.

Results: A pooled study analysis showed statistically significant changes from baseline in subjective nasal congestion for $0.05 \%$ oxymetazoline and vehicle at each hourly time-point from Hour 1 through Hour 12 (marginally significant at Hour 11). An objective measure of nasal flow was statistically significant at each time-point up to 12 hours. Adverse events on either treatment were infrequent. The number of subjects who achieved an improvement in subjective nasal congestion scores of at least 1.0 was significantly higher in the Oxy group vs. vehicle at all hourly time-points on a 6-point nasal congestion scale.

Conclusions: This study shows for the first time, that oxymetazoline provides both statistically significant and clinically meaningful relief of nasal congestion and improves nasal airflow for up to 12 hours following a single dose.

Key words: oxymetazoline, rhinitis, nasal decongestants, rhinomanometry, common cold

\section{Introduction}

Upper respiratory tract infections are associated with a significant degree of nasal mucosal inflammation and vasodilation, increased nasal blood flow, and increased vascular permeability (1). The resulting engorgement of nasal venous sinusoids and swelling of the nasal turbinates results in a physical reduction in the size of the nasal passages that restricts airflow and can be experienced by the patient as nasal congestion or blocked nose ${ }^{(1)}$. Oxymetazoline hydrochloride is an ingredient found in many topical nasal decongestant sprays with a long history ( $>50$ years) of safe use, when used as directed on the product label (3-10 days). It is a partial a2-adrenergic receptor agonist and selective a1-adrenergic receptor agonist ${ }^{(2)}$. Oxymetazoline, when applied topically, acts directly on these receptors in the nasal cavity to induce nasal vasoconstriction, reduced nasal turbinate volume, increased nasal patency which is experienced by subjects as freer breathing through the nose ${ }^{(2-4)}$. Approved product labels for nasal sprays containing $0.05 \%$ oxymetazoline around the globe vary, but state that the product provides relief of nasal congestion due to 'rhinitis,' 'sinusitis', 'cold', 'common cold,' 'hay fever,' 'vasomotor rhinitis' and/or 'upper respiratory allergies'. Given the mechanism of action of this medicine, it is not surprising that it provides nasal congestion relief of various etiologies. Importantly, the duration of use for products containing oxymetazoline are typically limited to 10 days or less due to an increased risk of patients exhibiting symptoms of rhinitis medicamentosa ${ }^{(5)}$.

In people suffering from common cold, nasal congestion (also referred to as 'stuffy nose,' 'blocked nose' or 'clogged nose') is 
reported to be one of the most bothersome symptoms during a cold or allergy episode ${ }^{(6-13)}$. This has been confirmed in a 4-year prospective study investigating the progression of acute upper respiratory infection symptom development and severity ${ }^{(8)}$ that demonstrated that nasal congestion was the most bothersome and most frequently reported symptom of a cold; it received the largest number of "severe" and "very severe" assessments while other symptoms such as cough, sneezing and runny nose and sore throat were rated between "mild" and "moderate". In a recent retrospective survey of cold sufferers $(N=3,333)$, nasal congestion was reported as a typical symptom during a cold by $69.5 \%$ of subjects and as the most bothersome symptom by $57.5 \%$ of respondents exceeding even cough and other common cold symptoms ${ }^{(6)}$. In this same survey, $52 \%$ percent of respondents said cough/cold impacted daily life a "fair amount" to "a lot" and almost 60\% (58.5\%) reported difficulty sleeping as "moderate" to "extreme" (13). Taken together, nasal congestion is established as having a negative impact on the sufferers' life, including disrupted sleep.

Decongestant efficacy is assessed subjectively using symptom scales (categorical or visual analogue scales (VAS)) or objectively using rhinomanometric measurements of nasal airway resistance (patency) and/or nasal volume) ${ }^{(12,14-18)}$. Direct application of oxymetazoline into the nasal cavity accounts for its fast action, providing relief from nasal congestion in less than 5 minutes ${ }^{(19,20)}$, with a duration of effect reported between 8 and 12 hours ${ }^{(3)}$. Oxymetazoline's long history of use underscores its safety-in-use, when used as directed. Herein we report the results of 2 prospective, randomized, double-blind, single-dose, vehicle-controlled, parallel studies which examined the duration of effect of oxymetazoline) in subjects suffering from nasal congestion due to self-diagnosed "common cold". To strengthen the conclusions, we have combined the results of these 2 studies.

\section{Materials and methods}

\section{Subjects}

Two clinical studies were conducted both with prospective, randomized, double-blind, single-dose, vehicle-controlled (isotonic saline), and of parallel design to investigate the onset of action and the duration of effect of a single dose of $0.05 \%$ oxymetazoline nasal spray in acute rhinitis. The objective of study 1 was to evaluate the decongestant activity of $0.05 \%$ oxymetazoline $\left(\right.$ Sinex $\left.{ }^{\oplus}\right)$ in patients with acute rhinitis up to 12 hours. The second study was conducted to confirm the 12-hour duration of effect of $0.05 \%$ oxymetazoline (Sinex ${ }^{\oplus}$ ) and to determine if prior history of allergic rhinitis might impact efficacy. The study protocols followed the Helsinki declaration (1964) and were approved by an Institutional Review Board: (for study 1, University Human investigations and studies committee at University of Kentucky; for study 2, Investigational Review Committee of Holy
Name Hospital, Teaneck, NJ, USA); all subjects provided informed consent. The two studies were conducted during two consecutive cold seasons in New Jersey. Male and female subjects, 18 year of age or older, who reported suffering from symptoms of an acute upper respiratory tract infection (i.e., self-diagnosed as "common cold") were enrolled during the cold weather months. Subjects were required to have a nasal airway resistance (NAR) of less than $2.7 \mathrm{~cm} \mathrm{H}_{2} \mathrm{O} /$ liter/sec. Subjects were excluded from the study if they had nasal cavity deformities (eg, nasal polyps, deviated septum), contraindicated disease (eg, hypertension, heart or thyroid disease, diabetes, chronic rhinitis), had used antihistamines or nasal decongestants in the 12 hours preceding the study (and none used 12- or 24-hour antihistamine products or intranasal corticosteroids), were sensitive to the active or inactive ingredients, were pregnant or nursing, or had a history of mood altering or illicit drug use. Subjects were stratified based on 3 distinct initial nasal airflow rates (Group I: $<0.025 \mathrm{~L}$ / sec; Group II: 0.25-0.39 L/sec; Group III: 0.40-0.55 L/sec) to ensure balance of nasal congestion severity amongst patients. Subjects administered 2 sprays of Oxy or control (isotonic vehicle) in each nostril consistent with the product labeling for a single dose of $0.05 \%$ oxymetazoline.

The only major difference between the 2 studies reported herein was the intentional recruitment of approximately half the subjects with a history of allergic rhinitis in the second study. Thus, for study 2 , the treatment groups were balanced for individuals who report a history of allergic rhinitis for $>2$ years and those who did not. Subjects with allergic rhinitis history had to have at least one of the following objective measures of allergic rhinitis: positive skin test, elevated total lgE, elevated serum radioallergosorbent test (RAST), evidence of nasal eosinophilia, or history of previous allergy injection treatment.

\section{Assessment of nasal congestion and nasal patency} Subjects assessed their feeling of nasal congestion hourly and for each nostril using a 6-point scale: 1) Nostril feels clear (no difficulty at all in breathing through this nostril); 2) Almost Clear (can breathe through this nostril quite easily); 3) Stuffy (can breathe with some hindrance enough to make me uncomfortable); 4) Quite Stuffy (nostril feels blocked and it is not comfortable breathing through this nostril); 5) Very Stuffy (can barely breathe through this nostril at all and have to breathe through my mouth much of the time); 6) Completely blocked (cannot breathe through this nostril at all). Nasal flow rates were assessed hourly objectively using anterior rhinomanometry ${ }^{(16,21,22)}$.

\section{Statistical methods}

All efficacy analyses were completed using the Intent-to-treat (ITT) population. The ITT population comprised all participants who were randomized and dosed. The primary time-point of interest was 12-hour assessment and an analysis of covariance 
(ANCOVA) was used for analyzing nasal flow rate and subjective nasal congestion at this time-point. The treatment differences were tested using an ANCOVA model that included relevant baseline measure as a covariate, study as independent variable (fixed factor), treatment groups as independent variable (fixed factor) and allergic rhinitis history (yes/no) as independent variable (fixed factor). Additional time-points (1 to 11 hour increments by 1 hour) were tested separately using the above ANCOVA model. There are various ways to address minimal important difference (MID) of subjective data, including anchor-based and distribution-based methods. Evidence has suggested that the MIDs determined by anchor-based approaches are consistently approximately one half a standard deviation (SD) based on the distribution of responses ${ }^{(23,24)}$. The standard deviation estimate from the 2 pooled trials at 12 hours was determined to be 0.74 . Assuming the MID is one half of the SD, this SD gives an MID of 0.37. An additional anchor based MID was developed by Barnes to assess differences in allergic rhinitis. Barnes assessed data from nine randomized, blinded, placebo-controlled clinical trials in intermittent and persistent allergic rhinitis ${ }^{(25)}$. Converting Barnes anchor based approach to the 6-point scale would translate to MID of $\approx 0.14$. Values were inflated to rounded increments of 0.5 and 1.0 unit to assess responder cut-offs. Meaningful responder cutoffs ( $\leq-0.5$ and $\leq-1.0$ ) of subjective nasal congestion response were analyzed by Cochran-Mantel-Haenszel (CMH) statistic testing treatment difference for responder cutoff controlling for study. The $\mathrm{CMH}$ tests were done separately for each post-treatment time-point ( 1 to 12 hour increments by 1 hour). Along with $\mathrm{CMH}$ test, corresponding odds ratio were reported. Hypotheses were tested at a two-sided significance level of $5 \%$. All analyses were done in SAS version 9.4 (SAS Institute, Cary, NC, USA).

\section{Results}

Demographics and baseline characteristics

A similar number of subjects were enrolled in Study 1 and Study 2 and between the 2 treatment groups (Table 1). Combined, the 2 studies enrolled 64 subjects in each group. Ages were similar between treatments in both studies with median ages ranging from 20-22 years. Approximately two-thirds of the enrolled subjects in both studies were male, and two-thirds of the enrolled subjects did not have a history of allergic rhinitis. Baseline reported nasal congestion and objective nasal flow rates were similar between the 2 treatments in both studies with a median nasal congestion score of 3.5 corresponding to the subjective assessment between 3-"Stuffy" and 4-"Quite Stuffy" and median flow rate of $0.36 \mathrm{~L} / \mathrm{sec}$ and $0.33 \mathrm{~L} / \mathrm{sec}$ for oxymetazoline and vehicle groups, respectively.

\section{Subjective nasal congestion}

Subjective reporting of nasal congestion was assessed at base-
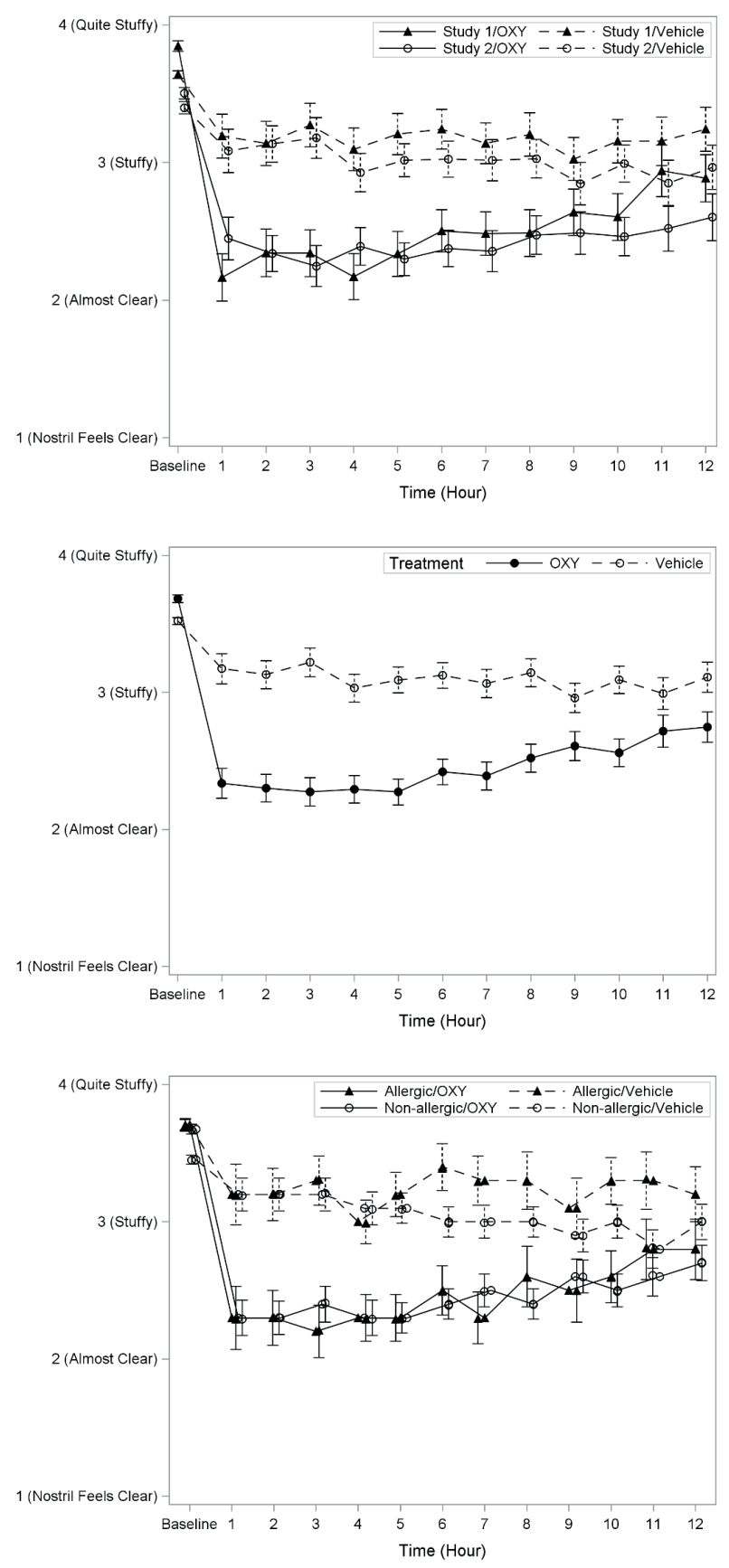

Figure 1. Subjective nasal congestion adjusted mean (SE) by time (hours). A) Lines reflect treatment and study B) Lines reflect treatment. C) Lines reflect treatment and allergic rhinitis status. Baseline mean is raw mean and post-treatment means are adjusted means.

line and over a 12-hour period. The populations experienced similar nasal congestion scores at baseline and demonstrated similar oxymetazoline relief over the dosing interval (Figure 1A).

Given the similar study designs and results, we also examined the data collectively. When the data from these studies were combined, a statistically significant $(p<0.02)$ change from 
Table 1. Summary of demographics and baseline characteristics.

\begin{tabular}{|c|c|c|c|c|c|c|}
\hline \multirow[b]{2}{*}{$\begin{array}{c}\text { Parameter } \\
\text { Statistic/Category }\end{array}$} & \multicolumn{2}{|c|}{ Study \#1 } & \multicolumn{2}{|c|}{ Study \#2 } & \multicolumn{2}{|c|}{ Combined Studies } \\
\hline & $\begin{array}{l}\text { OXY Nasal Spray } \\
(\mathrm{N}=34)\end{array}$ & $\begin{array}{l}\text { Isotonic Vehicle } \\
\qquad(\mathbf{N}=\mathbf{3 3})\end{array}$ & $\begin{array}{l}\text { OXY Nasal Spray } \\
\qquad(\mathrm{N}=\mathbf{3 0})\end{array}$ & $\begin{array}{l}\text { Isotonic Vehicle } \\
\qquad(\mathrm{N}=\mathbf{3 1})\end{array}$ & $\begin{array}{l}\text { OXY Nasal Spray } \\
(\mathrm{N}=64)\end{array}$ & $\begin{array}{l}\text { Isotonic Vehicle } \\
\qquad(N=64)\end{array}$ \\
\hline \multicolumn{7}{|l|}{ Age (yr) } \\
\hline $\mathrm{N}$ & 34 & 33 & 30 & 31 & 64 & 64 \\
\hline Min-Max & $18.0-36.0$ & $18.0-41.0$ & $18.0-41.0$ & $16.0-37.0$ & $18.0-41.0$ & $16.0-41.0$ \\
\hline Mean (SD) & $23.3(5.36)$ & $22.1(5.10)$ & $24.3(6.69)$ & $23.3(5.38)$ & $23.8(5.99)$ & $22.7(5.23)$ \\
\hline Median & 21.5 & 20.0 & 21.5 & 22.0 & 21.5 & 21.0 \\
\hline \multicolumn{7}{|l|}{$\operatorname{Sex} n(\%)$} \\
\hline Female & $13(38.2 \%)$ & $11(33.3 \%)$ & $9(30.0 \%)$ & $12(38.7 \%)$ & $22(34.4 \%)$ & $23(35.9 \%)$ \\
\hline Male & $21(61.8 \%)$ & $22(66.7 \%)$ & $21(70.0 \%)$ & $19(61.3 \%)$ & $42(65.6 \%)$ & $41(64.1 \%)$ \\
\hline \multicolumn{7}{|l|}{ Allergic Rhinitis History } \\
\hline No & $29(85.3 \%)$ & $25(78.1 \%)$ & $14(46.7 \%)$ & $19(57.6 \%)$ & $43(67.2 \%)$ & $44(67.7 \%)$ \\
\hline Yes & $5(14.7 \%)$ & $7(21.9 \%)$ & $16(53.3 \%)$ & $14(42.4 \%)$ & $21(32.8 \%)$ & $21(32.3 \%)$ \\
\hline \multicolumn{7}{|c|}{ Baseline Subjective Nasal Congestion (Scale 1-6)* } \\
\hline $\mathrm{N}$ & 33 & 32 & 30 & 31 & 63 & 63 \\
\hline Min-Max & $2.5-5.5$ & $3.0-5.0$ & $2.0-5.0$ & $1.5-4.5$ & $2.0-5.5$ & $1.5-5.0$ \\
\hline Mean (SD) & $3.8(0.78)$ & $3.6(0.53)$ & $3.5(0.78)$ & $3.4(0.85)$ & $3.7(0.79)$ & $3.5(0.71)$ \\
\hline Median & 3.5 & 3.5 & 3.5 & 3.5 & 3.5 & 3.5 \\
\hline \multicolumn{7}{|c|}{ Baseline Nasal Flow Rate (L/sec) } \\
\hline $\mathrm{N}$ & 31 & 29 & 30 & 33 & 61 & 62 \\
\hline Min-Max & $0.05-0.57$ & $0.03-0.55$ & $0.08-0.57$ & $0.11-0.58$ & $0.05-0.57$ & $0.03-0.58$ \\
\hline Mean (SD) & $0.35(0.12)$ & $0.35(0.12)$ & $0.35(0.12)$ & $0.34(0.11)$ & $0.35(0.12)$ & $0.34(0.12)$ \\
\hline Median & 0.38 & 0.37 & 0.36 & 0.32 & 0.36 & 0.33 \\
\hline
\end{tabular}

$\mathrm{N}=$ number of subjects within specified treatment. $\mathrm{N}(\%)=$ number and percentage of subjects within specified treatment, parameter, and category. *Nasal congestion scale: 1-Nostril Feels Clear, 2-Almost Clear, 3-Stuffy, 4-Quite Stuffy, 5-Very Stuffy, and 6-Completely Blocked. OXY = 0.05\% oxymetazoline nasal spray.

baseline was observed between $0.05 \%$ oxymetazoline and vehicle at each hourly time-point from Hour 1 through Hour 12 (marginally significant, $\mathrm{p}=0.0858$ at Hour 11 ; Table 2, Figure 1B) with highly statistically significant differences $(p<0.001)$ at Hours 1 through 8 . Results from Study \#1 seemed to suggest that subjects with a history of allergic rhinitis may have a different response to oxymetazoline than non-allergic subjects, although the number of subjects with a history of allergic rhinitis in this study, were too small to draw conclusions. To address this question, in Study \#2, subjects suffering from acute rhinitis were recruited equally with and without a history of allergic rhinitis. Pooled analysis of Study \#1 and \#2 did not provide evidence that a previous allergic rhinitis diagnosis had any impact on the efficacy of oxymetazoline spray (Figure 1C).

To examine the clinical meaningfulness of the treatment effect, we compared improvements from baseline nasal congestion relief of greater than a half unit $(\geq 0.5)$ and more than a full unit
( $\geq 1.0$ ). Importantly, 11 of 12 hourly assessments demonstrated an improvement in nasal congestion scores of at least 0.5 magnitude in the oxymetazoline treatment group vs. the vehicle $(p<0.01)$, while 12 of 12 assessments were of at least 1.0 magnitude ( $p \leq 0.02$ vs. vehicle; Table 3 ). The odds ratio at 12 hours post-dose revealed that subjects receiving $0.05 \%$ oxymetazoline were $>3$ times more likely to have a beneficial decrease of $\geq 0.5$ and $\geq 1.0$ than those receiving vehicle $(p \leq 0.003)$.

\section{Objective nasal flow rates}

Objective nasal flow rates were determined at baseline and over a 12-hour period for both Study 1 and Study 2. In both studies, oxymetazoline provided a significant improvement in nasal airflow over the entire 12-hour dosing interval (Figure 2A). Combining the nasal flow rates from both studies demonstrated a statistically significant increase $(p<0.01)$ in nasal flow between the $0.05 \%$ oxymetazoline and vehicle treatments at each hourly time-point from Hour 1 through Hour 12 (Table 4, Figure 2B) 
Table 2. Pooled analysis of studies 1 and 2 change from baseline subjective nasal congestion.

\begin{tabular}{ccccc} 
Hours & \multicolumn{4}{c}{ Adjusted Mean (SE) } \\
OXY Nasal & $\begin{array}{c}\text { Isotonic } \\
\text { Spray }\end{array}$ & $\begin{array}{c}\text { Vehicle } \\
\text { Difference } \\
\text { (SE) }\end{array}$ & P-value \\
\hline 1 & $-1.3(0.11)$ & $-0.4(0.11)$ & $-0.8(0.15)$ & $<.0001$ \\
\hline 2 & $-1.3(0.10)$ & $-0.5(0.10)$ & $-0.8(0.14)$ & $<.0001$ \\
\hline 3 & $-1.3(0.10)$ & $-0.4(0.10)$ & $-0.9(0.14)$ & $<.0001$ \\
\hline 4 & $-1.3(0.10)$ & $-0.6(0.10)$ & $-0.7(0.14)$ & $<.0001$ \\
\hline 5 & $-1.3(0.09)$ & $-0.5(0.09)$ & $-0.8(0.13)$ & $<.0001$ \\
\hline 6 & $-1.2(0.09)$ & $-0.5(0.09)$ & $-0.7(0.13)$ & $<.0001$ \\
\hline 7 & $-1.2(0.10)$ & $-0.5(0.10)$ & $-0.7(0.14)$ & $<.0001$ \\
\hline 8 & $-1.1(0.10)$ & $-0.5(0.10)$ & $-0.6(0.14)$ & $<.0001$ \\
\hline 9 & $-1.0(0.11)$ & $-0.6(0.11)$ & $-0.4(0.14)$ & 0.0161 \\
\hline 10 & $-1.1(0.10)$ & $-0.5(0.10)$ & $-0.5(0.14)$ & 0.0002 \\
\hline 11 & $-0.9(0.12)$ & $-0.6(0.12)$ & $-0.3(0.16)$ & 0.0858 \\
\hline 12 & $-0.9(0.11)$ & $-0.5(0.11)$ & $-0.4(0.15)$ & 0.0173 \\
\hline
\end{tabular}

OXY $\mathrm{N}$ ranges from 60-63 and vehicle $\mathrm{N}$ is $62-63$ for various timepoints (data not shown). $\mathrm{OXY}=0.05 \%$ oxymetazoline nasal spray.

with highly statistically significant differences $(p<0.001)$ at Hours 1 through 10 . As observed for subjective relief, nasal flow rates were similar regardless of a history of allergic rhinitis as evidence by a lack of statistical significance at all timepoint, with the exception of hour 5 ( $p=0.044$ ) (Figure $2 C$ ).

\section{Adverse events}

Adverse events were generally mild, consisting of one subject on the oxymetazoline treatment complaining of a burning sensation in the sinuses in study 1 . One subject on oxymetazoline treatment reported sinus pain and another subject reported a burning sensation on left side ear and nostril, while subjects receiving vehicle results in one subject reporting itchy nose and eyes, and another subject reported chills and sweating in study 2.

\section{Discussion}

This investigation shares the results of 2 well-controlled clinical studies and provides the first evidence to support a twice-a-day (12 hour) dosing schedule for oxymetazoline $(0.05 \%)$ for both subjective relief and nasal airflow. While a retrospective analysis of the first clinical investigation provided some evidence that an underlying diagnosis of allergic rhinitis may impact the sensitivity to oxymetazoline, results of a second, prospectively designed study failed to corroborate this finding for either subjective reports of nasal congestion or objective nasal airflow. The results of the current investigation are consistent with the findings of Kishore et al. ${ }^{(26)}$, which used computational fluid
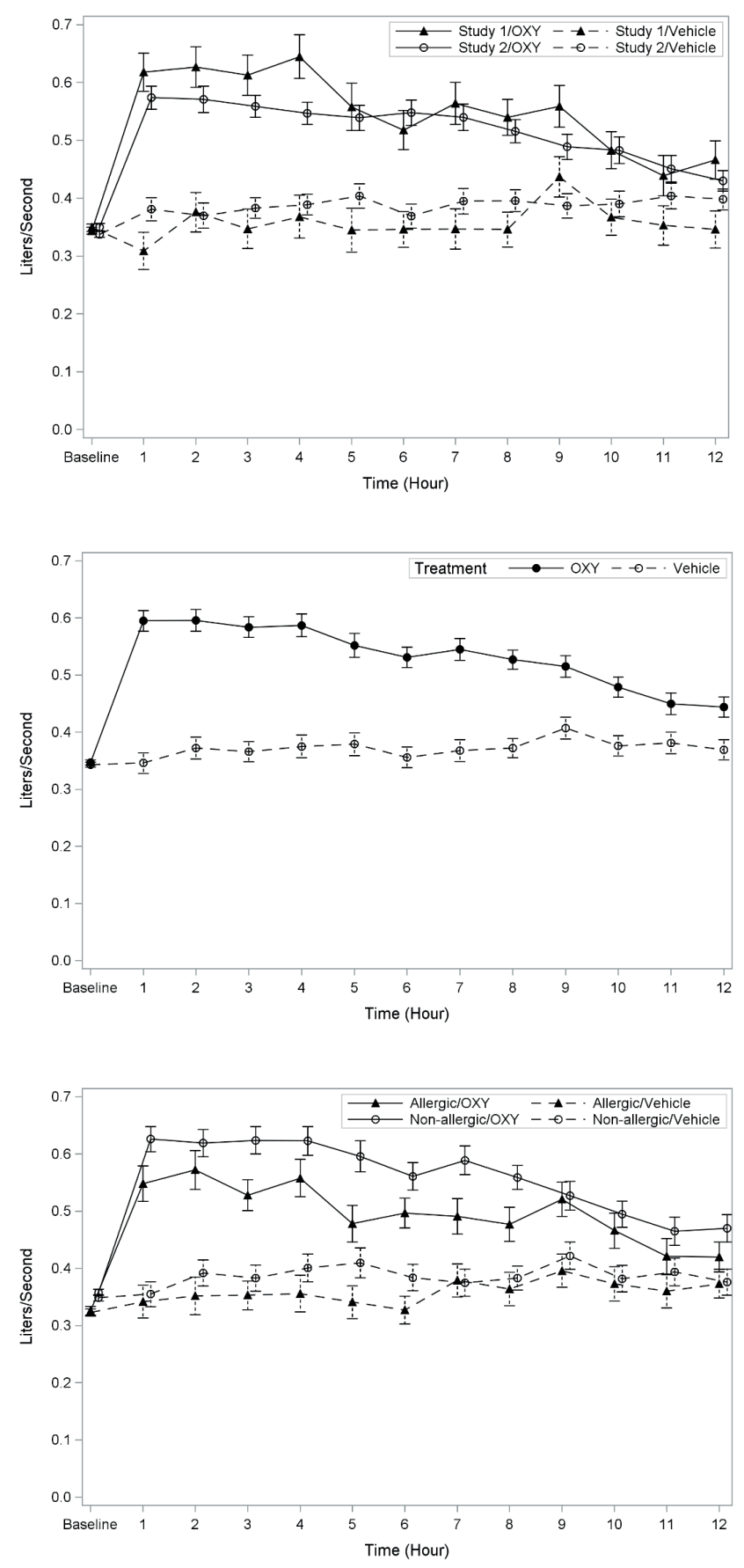

Figure 2. Nasal flow rate adjusted mean (SE) by time (hours). A) Lines reflect treatment and study B) Lines reflect treatment. C) Lines reflect treatment and allergic rhinitis status. Baseline mean is raw mean and post-treatment means are adjusted means.

dynamics of MRI data which predicted a $50 \%$ reduction in nasal resistance and improved nasal airflow for a $0.05 \%$ oxymetazoline spray compared to sham treatment at 12 hours post-dose. While Kishore et al. ${ }^{(26)}$ predicted air flow improvements at 12 hours, subjective endpoints were not included. A strength of the current pooled analysis is that it includes two studies which col- 
Table 3. Change from baseline subjective nasal congestion response cut-offs and percent responding by hour and treatment for pooled studies 1 and 2.

\begin{tabular}{|c|c|c|c|c|c|}
\hline Hour & Responder Cut-offs & $\begin{array}{c}\text { OXY Nasal Spray } \\
\qquad n \%\end{array}$ & $\begin{array}{c}\text { Isotonic Vehicle } \\
\text { n \% }\end{array}$ & Odds Ratio & $\begin{array}{c}\text { CMH } \\
\text { P-value }\end{array}$ \\
\hline \multirow[t]{2}{*}{1} & $\leq-0.5$ & $51(81.0 \%)$ & $30(48.4 \%)$ & 4.65 & 0.0001 \\
\hline & $\leq-1.0$ & 41 (65.1\%) & $17(27.4 \%)$ & 5.10 & $<.0001$ \\
\hline \multirow[t]{2}{*}{2} & $\leq-0.5$ & $54(87.1 \%)$ & 38 (61.3\%) & 4.28 & 0.0010 \\
\hline & $\leq-1.0$ & $40(64.5 \%)$ & $17(27.4 \%)$ & 4.86 & $<.0001$ \\
\hline \multirow[t]{2}{*}{3} & $\leq-0.5$ & 55 (88.7\%) & 35 (55.6\%) & 6.38 & $<.0001$ \\
\hline & $\leq-1.0$ & 44 (71.0\%) & $20(31.7 \%)$ & 5.33 & $<.0001$ \\
\hline \multirow[t]{2}{*}{4} & $\leq-0.5$ & 57 (90.5\%) & 41 (66.1\%) & 4.84 & 0.0010 \\
\hline & $\leq-1.0$ & $42(66.7 \%)$ & $23(37.1 \%)$ & 3.39 & 0.0010 \\
\hline \multirow[t]{2}{*}{5} & $\leq-0.5$ & $58(95.1 \%)$ & 39 (61.9\%) & 12.34 & $<.0001$ \\
\hline & $\leq-1.0$ & $44(72.1 \%)$ & $19(30.2 \%)$ & 6.13 & $<.0001$ \\
\hline \multirow[t]{2}{*}{6} & $\leq-0.5$ & $56(90.3 \%)$ & 37 (59.7\%) & 6.30 & $<.0001$ \\
\hline & $\leq-1.0$ & $46(74.2 \%)$ & $22(35.5 \%)$ & 5.15 & $<.0001$ \\
\hline \multirow[t]{2}{*}{7} & $\leq-0.5$ & $56(88.9 \%)$ & 39 (62.9\%) & 4.85 & 0.0007 \\
\hline & $\leq-1.0$ & $43(68.3 \%)$ & $20(32.3 \%)$ & 4.56 & $<.0001$ \\
\hline \multirow[t]{2}{*}{8} & $\leq-0.5$ & 54 (85.7\%) & 37 (58.7\%) & 4.39 & 0.0007 \\
\hline & $\leq-1.0$ & $43(68.3 \%)$ & $18(28.6 \%)$ & 5.38 & $<.0001$ \\
\hline \multirow[t]{2}{*}{9} & $\leq-0.5$ & $50(79.4 \%)$ & $43(68.3 \%)$ & 1.78 & 0.1621 \\
\hline & $\leq-1.0$ & 40 (63.5\%) & 22 (34.9\%) & 3.25 & 0.0014 \\
\hline \multirow[t]{2}{*}{10} & $\leq-0.5$ & $52(85.2 \%)$ & 39 (61.9\%) & 3.54 & 0.0038 \\
\hline & $\leq-1.0$ & 40 (65.6\%) & 24 (38.1\%) & 3.10 & 0.0023 \\
\hline \multirow[t]{2}{*}{11} & $\leq-0.5$ & 50 (79.4\%) & $36(57.1 \%)$ & 2.88 & 0.0079 \\
\hline & $\leq-1.0$ & 41 (65.1\%) & $28(44.4 \%)$ & 2.33 & 0.0208 \\
\hline \multirow[t]{2}{*}{12} & $\leq-0.5$ & 49 (81.7\%) & 36 (57.1\%) & 3.36 & 0.0033 \\
\hline & $\leq-1.0$ & 37 (61.7\%) & 20 (31.7\%) & 3.50 & 0.0009 \\
\hline
\end{tabular}

$\mathrm{OXY}=0.05 \%$ oxymetazoline nasal spray.

lected both subjective and objective end points with significant effects observed at 12 hours. We believe the results up to 12 hours are clinically meaningful based on the responder cutoffs between 0.5 and 1.0. In addition, these cutoffs exceed minimal important differences defined by Norman et al. ${ }^{(23,24)}$ and Barnes et al. ${ }^{(25)}$ as described in the methods section. Further, in the present analysis the odds ratio predicts that subjects were greater than 3 times more likely to achieve a significant responder cutoff ( 0.5 and 1.0) on oxymetazoline relative to control (Table 3 ) at the 12-hour assessment.

The demonstration of 12 hours of symptom relief for an oxymetazoline nasal spray has several implications for those seeking options to control their nasal congestion. First, these data suggest nasal congestion sufferers could adopt a simple and convenient dosing paradigm including a morning spray and another before bedtime over the short-term duration of a cold. The use of such a product to relieve nasal congestion before bed would be consistent with the large number of acute rhinitis sufferers expressing difficulties sleeping ${ }^{(13)}$. Another implication of establishing a 12-hour dosing interval for the product tested is that the dosing schedule is in line with the availability of 12hour antihistamines for treating acute rhinitis and could result in better patient compliance and, thus, symptom relief.

The efficacy of oxymetazoline has been well known for decades. However, it is worth noting that topical, nasal products for the treatment of acute rhinitis can have side effects if the sufferer uses the product outside of the instructions. For example, longterm use of topical nasal decongestants has been associated with an increased risk of developing rhinitis medicamentosa (RM) by an undefined mechanism. For this reason, product labels typically limit the duration of use to less than 10 days. Despite the consistency of the efficacy data between the two studies, there are limitations to the results. First, both of the 
Table 4. Pooled analysis of studies 1 and 2 change from baseline nasal flow rate $(\mathrm{I} / \mathrm{sec})$.

\begin{tabular}{ccccc}
\multicolumn{5}{c}{ Adjusted Mean (SE) } \\
Hours & $\begin{array}{c}\text { OXY Nasal } \\
\text { Spray }\end{array}$ & $\begin{array}{c}\text { Isotonic } \\
\text { Vehicle }\end{array}$ & $\begin{array}{c}\text { Difference } \\
\text { (SE) }\end{array}$ & P-value \\
\hline 1 & $0.25(0.018)$ & $0.00(0.018)$ & $0.25(0.025)$ & $<.0001$ \\
\hline 2 & $0.25(0.019)$ & $0.03(0.019)$ & $0.22(0.026)$ & $<.0001$ \\
\hline 3 & $0.24(0.018)$ & $0.02(0.018)$ & $0.22(0.025)$ & $<.0001$ \\
\hline 4 & $0.24(0.020)$ & $0.03(0.020)$ & $0.21(0.027)$ & $<.0001$ \\
\hline 5 & $0.21(0.021)$ & $0.04(0.020)$ & $0.17(0.028)$ & $<.0001$ \\
\hline 6 & $0.19(0.018)$ & $0.01(0.018)$ & $0.17(0.024)$ & $<.0001$ \\
\hline 7 & $0.20(0.019)$ & $0.02(0.019)$ & $0.18(0.027)$ & $<.0001$ \\
\hline 8 & $0.18(0.017)$ & $0.03(0.017)$ & $0.15(0.024)$ & $<.0001$ \\
\hline 9 & $0.17(0.019)$ & $0.06(0.019)$ & $0.11(0.026)$ & $<.0001$ \\
\hline 10 & $0.14(0.018)$ & $0.03(0.018)$ & $0.10(0.025)$ & $<.0001$ \\
\hline 11 & $0.11(0.019)$ & $0.04(0.019)$ & $0.07(0.026)$ & 0.0092 \\
\hline 12 & $0.10(0.018)$ & $0.03(0.018)$ & $0.07(0.025)$ & 0.0028 \\
\hline & & & & \\
\hline
\end{tabular}

OXY $\mathrm{N}$ ranges from $59-61$ and vehicle $\mathrm{N}$ is 62 for various time points (data not shown). OXY $=0.05 \%$ oxymetazoline nasal spray. studies were of similar design, but not identical. The first study disproportionately enrolled cold sufferers without a history of allergic rhinitis, while the second study specifically recruited half the subjects to better understand if a previous allergic rhinitis diagnoses impacted efficacy. In addition, these studies were single dose and it is of interest to understand if these effects would be repeatable in a long-term, multi-dose study.

\section{Acknowledgements}

The authors wish to thank Judith M. Pepin, PhD, for help in the preparation of this manuscript. All authors are responsible for the content and have read and approved the final manuscript.

\section{Authorship contribution}

All authors contributed to the analysis and interpretation of the data and manuscript preparation.

\section{Conflict of interest}

David Ramsey, Sanjay Karnati and Andrew N. Carr are currently full-time employees of the Procter \& Gamble Company.

Howard Druce MD is an allergist in private practice in Somerville $\mathrm{NJ}$ and Clinical Professor of Medicine, Division of Allergy/Immunology, Department of Internal Medicine, Rutgers - New Jersey Medical School, Newark, NJ, USA.

\section{References}

1. Naclerio RM, Bachert C, Baraniuk JN.Pathophysiology of nasal congestion. Int J Gen Med 2010; 3: 47-57.

2. Brayfield A (ed), Martindale: The Complete Drug Reference. [online] London: Pharmaceutical Press <http://www. medicinescomplete.com/> (accessed on [12/4/2016]).

3. Chen KS, Bharaj SS, King EC. Induction and relief of nasal congestion in ferrets infected with influenza virus. Int J Exp Pathol 1995; 76(1): 55-64.

4. Docherty JR. Subtypes of functional alpha1and alpha2-adrenoceptors. Eur J Pharmaco 1998; 361(1): 1-15

5. Graf $P$, Juto JE. Decongestion effect and rebound swelling of the nasal mucosa during 4-week use of oxymetazoline. ORL. 1994;56(3):157-60.

6. Blaiss MS, Dicpinigaitis PV, Eccles $R$, Wingertzahn MA. Consumer attitudes on cough and cold: US (ACHOO) survey results, Curr Med Res Opin 2015: 31(8); 1527-1538.

7. Blaiss MS, Meltzer EO, Derebery MJ, Boyle JM. Patient and healthcare-provider perspectives on the burden of allergic rhinitis. Allergy Asthma Proc. 2007; 28(Suppl.1): S4-10.

8. Witek TJ, Ramsey DL, Carr AN, Riker DK. The natural history of community-acquired common colds symptoms assessed over 4-years. Rhinology. 2015 Mar; 53(1): 81-8.
9. Allergies in America: A landmark survey of nasal allergy sufferers: Adult. Executive Summary. Conducted by HealthSTAR Communications, Inc, in partnership with Schulman, Ronca \& Bucuvales, Inc. 2006. URL: http://www.myallergiesinamerica. com/ Accessed on December 62016.

10. Juniper EF, Guyatt GH, Dolovich J. Assessment of quality of life in adolescents with allergic rhinoconjunctivitis: development and testing of a questionnaire for clinical trials. J Allergy Clin Immunol. 1994; 93: 413-23.

11. Shedden A. Impact of nasal congestion on quality of life and work productivity in allergic rhinitis. Findings from a large online survey. Treat Respir Med. 2005; 4: 439-46.

12. Cohen BM, Duffy EP. Physiological and clinical estimates of the relief of nasal flow obstruction in allergic rhinitis; effects of a topical decongestant (oxymetazoline). J Asthma Res 1969; 7(2): 65-73.

13. Dicpinigaitis PV, Eccles R, Blaiss MS, et al Impact of cough and common cold on productivity, absenteeism, and daily life in the United States: ACHOO survey. Curr Med Res Opin. 2015;31:1519-1525

14. Matson CJ, Welter AN, Kvam DC. An experimental non-invasive animal technique for measuring nasal airway resistance: adrenergic and antihistaminic agents. Arch Int Pharmacodyn Ther 1978; 232: 68-78.

15. Kjaergaard T, Cvancarova M, Steinsvag SK.
Nasal congestion index: a measure for nasal obstruction. Laryngoscope 2009; 119(8): 1628-32.

16. Nathan RA, Eccles R, Howarth PE, Steinsvag SK, Togias A. Objective monitoring of nasal patency and nasal physiology in rhinitis. J Allergy Clin Immunol 2005: 115: S442-S459.

17. Zhang G, Solomon P, Rival R, Fenton RS, Cole P. Nasal airway volume and resistance to airflow. Am J Rhinol 2008; 22: 371-375.

18. Passali D, Mezzedimi C, PassaliGC, NutiD, Bellusi L. The role of rhinomanometry, acoustic rhinometry, and mucociliary transport time in the assessment of nasal patency. Ear Nose Throat J. 2000; 79: 397-400).

19. Witek Jr TJ, Canestrari DA, Hernandez JR, Miller RD, Yang JY, Riker DK. Superficial nasal mucosal blood flow and nasal patency following topical oxymetazoline hydrochloride. Annals of allergy. 1992 Feb;68(2):165-8

20. Druce HM, Bonner RF, Patow CA, Choo PE, Summers RJ, Kaliner MA. Response of nasal blood flow to neurohormones as measured by laser-Doppler velocimetry. Journal of Applied Physiology. 1984 Oct 1;57(4):127683.

21. Cole P, Fenton RS. Contemporary rhinomanometry. J Otolaryngol 2006; 35(2): 83-7.

22. Davis SS, Eccles R. Nasal congestion: mechanisms, measurement and medications. Core information for the clinician. Clin Otolaryngol Allied Sci 2004; 29(6): 659-66.

23. Norman GR, Sloan JA, Wyrwich KW. 
Interpretation of changes in health-related quality of life: the remarkable universality of half a standard deviation. Medical care. 2003 May 1;41(5):582-92.

24. Norman GR, Sloan JA, Wyrwich KW. The truly remarkable universality of half a standard deviation: confirmation through another look. Expert Rev Pharmacoecon Outcomes Res. 2004 Oct;4(5):581-5.

25. Barnes ML, Vaidyanathan S, Williamson PA Lipworth BJ. The minimal clinically important difference in allergic rhinitis. Clin Exp Allergy. 2010 Feb;40(2):242-50.

26. Kishore A, Blake L, Wang C, Ba S, Gross
G. Evaluating the Effect of Sinex ${ }^{\oplus}(0.05 \%$ Oxymetazoline) Nasal Spray on Reduction of Nasal Congestion Using Computational Fluid Dynamics. J Biomech Eng. 2015; 137(8) 081011.
Andrew N. Carr, PhD

Procter \& Gamble

8700 Mason-Montgomery Rd.

Mason Ohio 45040

USA

Tel: +1-(513) 622-0928

Fax: +1-(513) 277-6305

E-mail:carr.an@pg.com 